\title{
Biochemical characterization of the Fibrobacter succinogenes endoglucanase EGC, analysis of its gene and protein domains
}

\author{
C Bera, E Forano, G Gaudet, Y Ribot \\ INRA, Laboratoire de Microbiologie, C.R. de Clermont-Ferand-Theix \\ 63122 Saint-Genès-Champanelle, France
}

\begin{abstract}
Fibrobacter succinogenes, a major cellulolytic rumen bacterium, possesses many different cellulases and hemicellulases. In order to elucidate the organization of the cellulasic system of this bacterium, many cellulase and xylanase genes have been cloned from the strain S85 in Escherichia coli, and their sequence determined (Forsberg et al, 1994, in: Genetics, Biochemistry and Ecology of lignocellulose degradation, Shimada et al, eds, Uni publishers Co, LTD, Tokyo, Japan, 125-136). An endoglucanase gene was previously cloned from the strain BL2 in E. coli (Harris, Gilmour and McConville, unpublished). The cloned DNA fragment was sequenced: an open reading frame encoding a protein of 620 amino acids named EGC was found. The protein sequence shows homology with the sequences of family $E$ cellulases (glycosyl-hydrolases family 9), and particularly family $\mathrm{E} 1$. The best homology is found with endoglucanase EGB from the strain $S 85$ of $F$. succinogenes (Forano et al, 1994, Current Microbiol, 28, 7-14; Broussolle et al, 1994, FEMS Microbiol Lett, 124, 439448). Alignment of the amino acid sequence of EGC with the sequences of EGB and the
\end{abstract}

other family $E 1$ cellulases revealed that, like $E G B, E G C$ is composed of a large catalytic domain of 453 amino acids, plus an adjoining domain of unknown function located in the $\mathrm{N}$-terminal part of the protein. Furthermore, EGC contains another domain of 60 amino acids at its $\mathrm{C}$-terminal part that is not present in EGB. The function of this domain, composed essentially of charged amino acids, is not known. Secondary structure prediction and Hydrophobic Cluster Analysis of the sequences of $E G B$ and EGC suggest that the 2 proteins have a very similar $2 \mathrm{D}$ structure. The two proteins synthesized by recombinant $E$. coli cells, show the same substrate specificity. However, the optimal $\mathrm{pH}$ and temperature for their activity are different : respectively 7.0 and $37^{\circ} \mathrm{C}$ for EGC and 6.3 and $30^{\circ} \mathrm{C}$ for $\mathrm{EGB}$. We are presently looking for the presence of a gene homologous to $E G C$ in other strains of $F$. succinogenes. Study of the location of EGC in F. succinogenes cells and of the conditions of expression of its gene, compared with that of EGB, will be necessary to assess the role of this endoglucanase in $F$. succinogenes. 